\title{
Diagnose-Specific Antibiotic Prescribing Patterns at the Otorhinolaryngology Inpatient Departments of Two Private Healthcare Facilities in Central India: A Five Year Observational Study
}

\section{Elisabeth Silfwerbrand \\ Karolinska Institutet}

\section{Sumeer Verma}

Ruxmaniben Deepchand Gardi Medical College

\section{Cora Sjökvist}

Karolinska Institutet

\section{Cecilia Stålsby Lundborg}

Karolinska Institutet

\section{Megha Sharma ( $\nabla$ megha.sharma@ki.se) \\ Karolinska Institutet https://orcid.org/0000-0001-9165-9393}

\section{Research article}

Keywords: Otorhinolaryngology, surgical prophylaxis, chronic suppurative otitis media, diagnose-specific antibiotic prescribing patterns, private healthcare sector, India

Posted Date: August 11th, 2019

DOI: https://doi.org/10.21203/rs.2.12556/v1

License: (c) (i) This work is licensed under a Creative Commons Attribution 4.0 International License. Read Full License

Version of Record: A version of this preprint was published at International Journal of Environmental Research and Public Health on October 23rd, 2019. See the published version at https://doi.org/10.3390/ijerph16214074. 


\section{Abstract}

Background Antibiotics are overprescribed in low-and-middle-income countries where the infection rate is high. The global paucity of standard treatment guidelines and reliable prescription data is a barrier to rationalise antibiotic use and combat antibiotic resistance. Moreover, there is a lack of diagnose-specific prescription data from high infection risk departments such as the otorhinolaryngology (ENT). The purpose of the study was to present diagnose-specific antibiotic prescribing patterns at ENT inpatient departments of a teaching hospital and a non-teaching hospital from Indian private healthcare sector. Methods Data of all consecutive inpatients at the department $(n=3527)$ were collected for five years (2008-2013). Analyses were conducted for inpatients aged $>15$ years $(n=2909)$ using the World Health Organization's methodologies. Patient records were divided into four diagnoses (indication) groups, i.e., surgical, non-surgical, chronic suppurative otitis media (CSOM) and others. Results Of 2909 inpatients, $51 \%$ had surgical diagnoses. An average of $83 \%$ inpatients in the clean surgery group, $78 \%$ in viral infection and $75 \%$ in noninfectious groups were prescribed antibiotics. CSOM was the most common diagnosis at both settings (883/2909 inpatients), where nearly $90 \%$ inpatients were prescribed antibiotics. Overall, third-generation cephalosporins and fluoroquinolones were most commonly prescribed. Conclusions This study highlights prescribing antibiotic to the unindicated diagnosis groups, i.e., clean surgeries, viral infections, and non-infectious diagnoses. Recommended single-prophylactic dose of antibiotic was not prescribed for the majority of clean-contaminated surgeries. Prolonged empirical prescribing and insignificant use of the microbiology laboratory was evident in both settings. A meticulous analysis of clean surgery group highlighted the universal applicability issue of available global guidelines.

\section{Background}

Antibiotics are overprescribed worldwide but the practice is more common in low- and middle-income countries (LMICs), where standard treatment guidelines are not available or implemented, and the infection rates are high (1, 2). Antibiotic resistance is an inevitable consequence of antibiotic consumption that limits the treatment options, increases morbidity, treatment failures, and mortality $(1,2)$. The World Health Organization (WHO) has recognised antibiotic resistance as a global public health threat and identified local prescribing surveillance studies as a crucial step to slow down the emergence of resistance $(1,2)$. National surveillance networks for the prescriptions, including antibiotics, do not exist in most LMICs and neither in India mainly due to financial, technical and human resource constraints, and scarcity of computerized medical record system (3). In LMICs where both the infection risk and use of the antibiotics are high $(1,2)$, the data collection can be initiated at smaller scales. These small-scale studies are useful to inform the decisions made and over time, can be scaled up to national surveillance. Based on an estimation of national pharmaceutical sales data of 71 countries in 2010 , India was the largest antibiotic consumer for humans (4). Thereby, India is also a presumed hub of antibiotic-resistant bacteria.

Antibiotics are prescribed profusely at healthcare facilities. These places also provide suitable conditions for rapid emergence and spread of antibiotic-resistant bacteria $(3,5,6)$. The few available surveillance studies from India primarily focus on public sector healthcare facilities $(5,7-10)$. However, a majority of the Indian population seek healthcare at private sector facilities, where the poor implementation of globally available guidelines and lack of local prescribing guidelines is evident $(5,8,11,12)$. Studies from high-income countries report high prescribing of antibiotics to the patients admitted to the otorhinolaryngology departments, commonly known as the department of ear, nose, and throat (ENT) $(13,14)$. Therefore, surveillance studies focusing departments with a high risk of infections in the private sector, such as ENT department, is crucial. In India, the patterns of antibiotic prescribing for 
ENT diagnoses have only been published from outpatient departments and primary healthcare facilities (15-17) and not from the inpatient departments of higher healthcare levels.

\section{Method}

The aim of the study was to present and compare the antibiotic prescribing patterns corresponding to the ENT diagnoses (indications), and further probing to the surgical and non-surgical indications, at the ENT departments of two private sector, tertiary healthcare hospitals, a teaching hospital (TH), and a non-teaching hospital (NTH), in Ujjain district of Central India.

\section{Study Design}

A cross-sectional study was conducted for all patients admitted for five years, 2008-2013, in the ENT inpatient departments at the TH and the NTH. The data were analysed and presented at the department level, diagnosis groups and specific diagnosis level.

\section{- Study Settings and Sample}

The two study hospitals are located in Ujjain district of Madhya Pradesh state in Central India. The study settings have been described in previous publications in detail (5). In brief, the study settings were a TH that is associated with a private medical college and an NTH. The TH is located in a rural area of Ujjain district and had 570 hospital beds at the time of the study. The healthcare policies of TH could be compared with the Indian public-sector healthcare facilities as it provided the medical care and medicines on a full charity basis to all patients visiting the hospitals. The NTH is situated in the city area of Ujjain (350 beds) where patients paid the subsidised cost for the medical consultations, prescribed medicines, and the diagnostics. Diagnostic facilities including microbiology laboratories were readily available at both study settings. Diagnose-specific standard treatment guidelines were not available at any of the study hospitals at the time of data collection.

The study population consisted of all consecutive patients admitted to the ENT departments of the two study hospitals. Data of a) the inpatients aged less than 15 years old, b) those that did not have an ENT related diagnosis or c) had incomplete patient records were excluded before analysis ( $n=550$, Figure 1 ). Patients who stayed for at least one night in the ENT wards were considered as inpatients and were included in the analysis.

\section{- Data Collection and Process of Analysis}

The data collection has been explained in detail in previous publications $(5,8)$. In short, the nurses were trained for manual data collection using a contextualised data collection tool. The tool included basic demographics, admission and discharge dates, description of prescribed antibiotics such as name, dose, duration and frequency, and the diagnoses. The data was entered in Epidata software 3.1 (http://www.epidata.dk/download.php) and Microsoft Excelß software.

Prescribed antibiotics were classified according to the WHO recommended methodologies, i.e., the Anatomical Therapeutic Chemical classification system (ATC) and the defined daily dose (DDD) to facilitate international comparison of the results (18). The indications assigned by the treating consultants in the patients' files were recorded at the time of discharge and were not verified externally. The indications were classified according to the International Classification of Diseases version 10 (ICD-10) (19). 
The study was focused on the anatomical and therapeutic main groups of the antibacterials for systemic use, with WHO suggested ATC code- J01 (18). The rate of diagnose-specific antibiotic prescription per patient and the percentage of antibiotic prescriptions adherent to the WHO Model Lists of Essential Medicines (WHOLEM) (20) and the National List of Essential Medicines of India (NLEM) were calculated (21). The oral metronidazole was classified with the systemic metronidazole with the ATC code of J01XD01 as indicated in NLEM (21). For the non-listed new fixed-dose combinations (FDC) of antibiotics, ATC codes were used as assigned by Sharma et al., using J01RA (5). Descriptive analysis was performed using Microsoft Excel and SPSS Version 23 (IBM, SPSS Inc., IL,

USA). Frequencies and percentages were calculated for categorical variables and the sum, median and range for numerical variables. Pearson's chi-square test was used to test the significance when comparing categorical variables. The level of significance was set to $<0.05$.

The inpatients were grouped, based on the assigned diagnoses, according to the guidelines of the United States of America (USA)(22) and the Scottish Intercollegiate Guidelines Network (SIGN)(23) to facilitate global comparison. Four diagnoses groups were formed namely, Group A, B, C and D (figure 1). Group A comprised of all inpatients with an indication of surgery. Group A was further divided into three subgroups based on the ENT surgical wounds classification system $(22,23)$ (table 1 and figure 1 ): subgroup A1- surgery in an area of manifest infection, i.e., contaminated/dirty surgery, A2- surgery in non-sterile tissue, i.e., clean-contaminated surgery and A3- clean surgery. Group B contained all non-surgical diagnoses, which were further divided into three subgroups; B1- clinical infection of bacterial, fungal or parasitic origin, B2- clinical infection of viral origin and B3- non-infectious indications, as presented in figure 1. Antibiotic treatment is recommended for the subgroups A1 and B1 and thus was not analysed extensively. In the present study, we have used the definition of surgical prophylactic antibiotic treatment, as presented in the SIGN classification system, i.e., the use of antibiotics before, during or after a diagnostic, therapeutic, or surgical procedure to prevent infectious complications (22)

\section{Table 1. The categories of ENT surgical wounds and the risk of surgical site infections as per available recommendations.}

The prevalence of chronic suppurative otitis media (CSOM) is high in the West Pacific, South East Asia and particularly in India (24). Antibiotics are commonly prescribed to patients with CSOM (24). Therefore, the prescriptions to the CSOM patients might influence the overall results of surgery patients. Thus, all patients with CSOM were categorised separately in group C. Group D contained other indications that could not be categorized in the groups $A, B$, and $C$ such as atrophic rhinitis. The prescriptions for group $D$ were not analysed in detail.

\section{Results}

Of the 3527 patients admitted to the ENT departments, 2909 were included in the analysis (Figure 1). Out of included inpatients, 2358 underwent surgical procedures. Of 2358, 883 had CSOM (group C, table 2) and the rest were categorised in group A. Group B, the non-surgical indications, consisted of 537 inpatients whereas 14 inpatients had other diagnoses (group D). In both hospitals, CSOM was most common among patients aged between 15 and 50 years, and cancers were most common among the patients aged more than 50 years.

Overall in group A, 85\% were prescribed antibiotics. At diagnosis group level, antibiotic prescribing was higher specifically in the dirty/contaminated surgery (A1) and clean-contaminated surgery (A2) subgroups at the NTH than at the $\mathrm{TH}$ (96\% each compared to $94 \%$ and $93 \%$ ) while it was higher in the clean surgery (A3) at the $\mathrm{TH}$ than at the NTH (86\% compared to $81 \%$, table 2). A diagnose-specific analysis of tonsillectomy and adenoidectomy in subgroup 
A3 showed that at the NTH, 36 patients underwent any of these surgeries and 32 were prescribed antibiotics with a median treatment period of 3 days (range: 1-6 days). At the TH out of the 109 patients who underwent tonsillectomy or adenoidectomy, 106 patients were prescribed antibiotics with a median treatment period of 6 days (range: 1-21 days). Moreover, a higher proportion of the prescriptions of subgroups A2 and A3 at the NTH adhered to the international prescribing guidelines (20-25\%) than at the TH (10-11\%). ${ }^{22,23}$ Overall, at the NTH, the proportion of prescriptions made using brand names (94\%) was higher when compared to that at the $\mathrm{TH}(55 \%)$.

CSOM (group C) was the most common diagnosis with $20 \%$ of total inpatients at the NTH and $33 \%$ at the TH (table 2). At both hospitals, group $C$ had the most extended duration of hospital stay and antibiotic treatment. Both durations were longer at that TH with a median of 11 days (range-1-38 days) and four days (range: 1-32 days) at the NTH. At the TH, 95\% of the inpatients with CSOM were prescribed antibiotics and $89 \%$ at the NTH. One patient with CSOM at the NTH was prescribed antibiotics ear drops.

In the non-surgery group (group B), antibiotics were prescribed to a higher proportion in all subgroups at the TH (83$94 \%)$ than at the NTH (75-92\%, table 2). In the non-infectious (subgroup B3), 75\% were prescribed antibiotics at the $\mathrm{NTH}$ and $83 \%$ at the TH.

Figure 2 presents $90 \%$ of the most commonly prescribed antibiotic substances ( $5^{\text {th }}$ level of ATC) at the diagnosis subgroup level, based on the drug utilisation $90 \%$ method (DU90\%). ${ }^{18,25}$ At a department level, ceftriaxone and FDCs were the drugs of choice at the NTH and ceftriaxone and ciprofloxacin at the TH. Of the total prescriptions, $24 \%$ at the NTH and 18\% at the TH were FDCs. A second-generation cephalosporin, cefuroxime (J01DC02), was prescribed at the NTH in subgroup A2 (17\%) but not at all at the TH. Among CSOM patients, ceftriaxone was most commonly prescribed in both hospitals followed by ciprofloxacin in the TH and FDCs in the NTH.

The duration of antibiotic prescription was highest in groups A, and C. Figure 3 presents the duration of antibiotics prescription in days to the inpatients of the groups $A$ and $C$ at the subgroup level. Among the patients in subgroup A2 (clean-contaminated surgery), $96 \%$ at the NTH and $93 \%$ at the TH were prescribed antibiotics for a longer duration than the recommended duration for this group (24 hours).

At discharge, a significantly higher number of patients were prescribed antibiotics at the $\mathrm{TH}(43 \%)$ than at the NTH $(33 \%, p<0.05)$. The patients in the surgical diagnosis groups ( $A$ and $C)$ were more often prescribed antibiotics than the patients in non-surgical group B. Overall, the FDCs of amoxicillin with clavulanic acid J01CR50 (45\%), cefuroxime J01DC02 (19\%) and ciprofloxacin J01MA02 (8\%) were the most commonly prescribed antibiotics at discharge.

Overall two deaths were reported at the $\mathrm{TH}$, one with CSOM and the other with tuberculosis. No co-morbidities were reported on these patients. Overall, the samples of $0.5 \%$ inpatients were sent for bacterial culture and antibiotic susceptibility tests from both settings. In total, the antibiotic therapy was changed in $0.4 \%$ prescriptions based on the microbiology culture and susceptibility reports.

\section{Discussion}

To the best of our knowledge, this is the first long-term study at diagnosis level that describes the pattern of antibiotic prescribing among ENT inpatients of Indian hospitals. Due to lack of ENT department-specific studies from the LMICs, we have compared our results with the studies of other departments. The present study highlights that antibiotics were prescribed to almost nine of the ten admitted patients (TH- $91 \%$ and NTH- $86 \%$ ). Antibiotics 
were prescribed most frequently and for the most prolonged period to the CSOM inpatients. Antibiotics were commonly prescribed for clean surgeries, clinically viral infections and non-infectious diagnoses. Overall, empiric treatment was extended during the entire hospital stay for most inpatients. One of the reasons for this extension might be paucity in sending samples for bacterial culture and antibiotic susceptibility tests. None of the inpatients was prescribed a single prophylactic dose of antibiotics, for clean-contaminated surgeries, as per recommendations $(22,23)$. Ceftriaxone and ciprofloxacin were predominantly prescribed in all groups. In India, increasing prevalence of bacteria resistant to carbapenems have been observed (4). Encouragingly, no carbapenem was prescribed at any of the ENT departments.

- $\quad$ Prescribing patterns in surgical diagnoses group, Group A

Among the patients who had clean-contaminated surgery, subgroup A2, a single dose regime of a first- or secondgeneration cephalosporin, preferably cefazolin, is recommended as prophylactic antibiotic treatment $(22,23)$. In our study, a third-generation cephalosporin was the preferred antibiotic choice in both settings. Similar results were shown in two studies conducted at general surgery department in Western India (26) and at a private tertiary healthcare hospital in Southern India (27), where third-generation cephalosporins were reported as the most commonly prescribed class of antibiotics. The preference to a broader spectrum antibiotic, such as the thirdgeneration cephalosporin, might be due to the overall increase in prevalence of bacterial resistance to antibiotics in India that has been observed in other settings (4).De-escalation of antibiotic therapy is suggested for settings where broad-spectrum antibiotics are the first drug of choice, but was not found at our settings (28). Overall, nine out of ten patients who underwent clean-contaminated surgery were prescribed prophylactic antibiotic treatment for more than one day. This might be due to a common global misunderstanding, as presented by Bratzler $\mathrm{D}$ et al., that longer prophylactic antibiotic treatment periods are considered to be more effective to prevent surgical site infections (SSI) than single dose regimes (23). Prescribing broad-spectrum antibiotics during a prolonged period as prophylactic antibiotic treatment is not recommended due to the increased risk of adverse effects, the risk of emergence of antibiotic resistance and higher treatment costs $(1,6,23)$.Studies to advocate prescribing a single dose of a first- or second-generation cephalosporin and to develop and introduce local prescribing guidelines based on the susceptibility patterns are also suggested.

Among the patients who underwent clean surgery (subgroup A3), 81\% at the NTH and $86 \%$ at the TH were prescribed antibiotics, even though prophylactic antibiotic treatment is not recommended for this subgroup (22, 23). Khan et al. from Southern India, reports that many surgeons often take a 'safety approach' and prescribe antibiotics to minimise the risk of SSI in clean surgeries(27). It is worth mentioning that the risk of SSI in clean surgery is reported to be less than $2 \%$ (22). Reasons to use a 'safety approach' could be a high patient burden per physician or presumed poor hygienic conditions of the patients as the catchment area included villages of low socio-economic status(28).All these presumptions need to be verified through a suggested qualitative study.

The results of antibiotic prescribing practices for tonsillectomy and adenoidectomy in the subgroup A3 highlights several underlying issues. The first issue was in accordance with a globally ongoing discussion. The discussion raises the question of whether antibiotics should be prescribed as a prophylactic antibiotic treatment to the patients undergoing tonsillectomy or adenoidectomy or not $(22,23,29)$. One side of the debate is presented by the USA and SIGN guidelines. These guidelines suggest to prescribed antibiotics as a general prophylactic antibiotic treatment for the above mentioned surgical procedures, but only to the patient's having risk factors of acquiring bacterial infections $(22,23)$. The other side of the debate presents a regional scenario based on local infection risk factors, as mentioned in a textbook of ENT diseases written by Indian authors (29).According to the recommendations of the 
book, prophylactic antibiotic treatment can be prescribed post-operatively up to a week (29). The ENT physicians at our study settings might have followed the local suggestion of prescribing antibiotics for the surgeries in question, and this could also explain the overall high proportion of antibiotic prescriptions in the subgroup A3.

Another issue raised was regarding universal applicability of a guideline. In the present study, the American and Scottish guidelines were used to facilitate the classification of the surgical indications concerned with prescribing of antibiotics (22). On the other hand, the local prescribing rationale suggests classifying tonsillectomy and adenoidectomy in subgroup A1, i.e., dirty/contaminated surgery and not in A3, i.e., clean surgery (29). Moreover, the use of different surgical techniques and varied access to the resources in a setting also affect the risk of surgical site infections and are a cause of prescribing antibiotics (30). Hence, the present diagnoses-specific study highlights our concern of applicability of available international guidelines, often based on surveillance data of high-income countries, to the other parts of the world especially to the LMICs. The antibiotic prescribing patterns of subgroup A3 supports the WHO's emphasis of development and implementation of local standard treatment guidelines based on local surveillance data of; the prescriptions, relevant risk factors for infections, the infrastructure of the healthcare system and availability of resources; to combat against antibiotic resistance (2).

\section{Prescribing patterns to the inpatients with non-surgical diagnoses, Group B}

Among the inpatients with non-surgical diagnoses, group $B$, antibiotic treatment is indicated only to the patients having a microbiologically confirmed or clinically estimated high risk of a bacterial infection (subgroup B1)(22, 23). A majority of the patients in subgroup B1 of both hospitals were prescribed antibiotics as per the recommendations. However, antibiotics are not indicated for clinical infections of suspected viral origin for subgroup B2 or noninfectious diseases, and subgroup B3 (31). Still, 76\% patients at the NTH and 84\% patients at the TH in these subgroups were prescribed antibiotics. There is a need to conduct a separate probing study to explore the underlying factors for this practice.

Furthermore, a longer duration of hospital stay has been reported to correspond to a higher risk of acquiring healthcare-associated infections (HAl) and increases the risk of being prescribed antibiotics (32). Thus, in the present study, a preventive approach for HAl might be the reason for the higher proportion of patients being prescribed antibiotics at the TH compared to the NTH. However, the DDD/100 prescriptions were higher at the NTH than at the $\mathrm{TH}$, pointing towards prescribing high antibiotic doses per prescription at the NTH. Prescribing antibiotics for non-indicated conditions, higher doses and for longer periods than indicated are considered as preventable factors that, if continued, might accelerate the increase in antibiotic resistance $(1,2,6)$.

- $\quad$ Prescribing patterns to the CSOM inpatients, Group C

CSOM was the most common diagnosis in our study settings. The procedures related to CSOM are categorised in classes comparable to subgroup A1 (dirty/contaminated surgery, e.g., emergency mastoidectomy), to which antibiotics should be prescribed as treatment and A3 (clean surgery, e.g., tympanoplasty), to which antibiotics should not be prescribed $(22,23,33)$. In group C, antibiotics were prescribed to $95 \%$ inpatients at the TH (NTH- $89 \%)$, and $91 \%$ were prescribed antibiotics for more than 48 hours (NTH- 74\%). The difference between the hospitals could be due to the presence of a higher number of contaminated/dirty surgeries performed at the TH than at the NTH. Furthermore, a WHO review article on CSOM, reports that topical antibiotics are superior to systemic antibiotics in terms of efficacy and have an advantage of less contribution to the development of antibiotic resistance (24). However, only one patient was prescribed antibiotic ear drops. The patients in group $\mathrm{C}$ at the $\mathrm{TH}$ had the most 
prolonged period of prescribed antibiotics with a median of 11 days. The lack of comparable antibiotic surveillance studies at ENT inpatient departments from the South-Asian region, lack of qualitative studies and consequently, the lack of antibiotics prescribing guidelines for CSOM surgeries restrict the possibilities to describe the reasons for this pattern antibiotic prescribing in the settings.

The new FDCs of antibiotics were prescribed at a lower extent (J01RA, Figure 2) as compared to the studies from departments at the study settings $(5,34)$. Most of the new FDCs of antibiotics have no underlying scientific justification and does not add to drug's efficacy; however, adds to the cost of therapy, increase adverse effects and encourages antibiotic resistance (35).Thus, less prescribing of new FDCs in both settings could be appreciated.

The low practice of sending samples for bacterial culture and antibiotic susceptibility tests at both settings resulted in extended empirical prescribing throughout the hospital stay. This is similar to a short term study conducted in the settings (5). Empiric treatment is used to start antibiotic therapy for a suspected bacterial infection after collection of a sample from the suspected infection site for susceptibility and culture tests (6). The empirical prescribing ought to be reassessed based on the microbiological results (6). The active CSOM infections are often polymicrobial, and the patients have in most cases received several antibiotic prescriptions at lower healthcare levels before visiting and being admitted at the tertiary level healthcare settings $(24,33)$. The high risk of multiple antibiotic treatments before hospital admission, suggests a low threshold for sending samples before initiating an empiric antibiotic therapy at the study settings, which was not observed (6). Results of our study highlight the need to conduct similar surveillance studies at other settings followed by contextualised qualitative studies to understand the underlying factors affecting the practitioners of the observed antibiotic prescribing patterns.

The strengths of this study were the long-term, continuous data collection, and detailed data at a diagnosis level recorded for all admitted patients. Furthermore, the data were from the private sector that provides healthcare to most of the Indian population. A limitation of this study was that perioperative notes were not included, which could have facilitated the interpretation of the results. However, this was not the objective of the present study. Although the data collection process was supervised robustly, the possibility of human error during data collection and entry cannot be denied. However, the possible effect of such human errors was expected to be minor due to the large study population, long study duration, robust monitoring, trained data recorders, and data entry staff. The establishment of the manual process of data collection, coding of antibiotics and indications and data entry explains why the data is analysed and published at the current time.

- $\quad$ Conclusions

The present study offers a unique insight into the otorhinolaryngology inpatient departments of the private healthcare sector in India and identifies several under-focused issues that need to be addressed in the future. In the present study, a high proportion of inpatients with non-indicated diagnoses, such as clean surgeries, viral infections and non-infectious indications were prescribed antibiotics. A deviation in diagnose-specific prescribing patterns, concerning the recommendations, indicates the issue of the general applicability of the guidelines prepared in the HIC in the LMICs. This highlights a need for the development of contextualised standard treatment guidelines based on local disease and prescribing data. Prescribing broad-spectrum antibiotics empirically and inadequate use of the microbiology laboratory was also observed in both hospitals.

The scarcity of surveillance studies of antibiotic prescribing is a limitation to develop prescribing guidelines in the LMICs. Similar surveillance studies are explicitly needed from the private healthcare settings of the LMICs. Our sustainable, low-cost solution of manual data collection could be adapted at the resource-constrained settings to 
reduce delays in conducting surveillance studies due to lack of computerization. Furthermore, the use of ATC/ DDD methodology and the ICD-10 codes make our results comparable and exchangeable to the other global studies. The findings of this study to formulate a standard policy and practice of the patterns of antibiotic prescribing in high infection risk inpatient's departments.

The issues raised in present communication need further probing using a qualitative approach for better understanding of the influencing factors for present prescribing patterns and possible areas of improvement. We also suggest developing customised educational workshops and group discussions as a part of antibiotic stewardship programmes among the prescribers to develop and implement diagnose-specific local antibiotic prescribing guidelines.

\section{Abbreviations}

- $\mathrm{WHO}=$ The World Health Organization

- ENT = Otorhinolaryngology = Ear, nose and throat

- $\mathrm{NTH}=$ Non-teaching hospital

- $\mathrm{TH}=$ Teaching hospital

- $\mathrm{ATC}=$ Anatomical Therapeutic Chemical classification

- DDD = Defined daily dose

- $I C D-10=$ International Classification of Diseases - version 10

- WHOLEM = WHO Model Lists of Essential Medicines

- $\mathrm{NLEM}=$ National List of Essential Medicines of India

- $F D C=$ Fixed-dose combinations

- USA = United States of America

- SIGN = Scottish Intercollegiate Guidelines Network

- $\mathrm{CSOM}=$ Chronic suppurative otitis media

- DU90\% = Drug utilisation $90 \%$ method

- $\mathrm{SSI}=$ Surgical site infection

- HAI = Healthcare-associated infection

\section{Declarations}

\section{Ethics Approval}

The present study was an observational study, and all measures were in place to maintain patients' confidentiality during data collection as well as analysis in accordance with the standard guidelines. None of the patients were contacted at any stage of the study and no patient was identified or analysed individualy. The data was analysed collectively forming various groups. The ethics committee of R. D. Gardi Medical College, Surasa, Ujjain, India approved the study with approval number: 41/2007 \& 114/2010. Following the norms of an observational study design, the need for approval of trial registration was waived off by the ehthics committee. 


\section{Consent for publication}

Not applicable

\section{Availability of data and material}

The datasets generated during the current study are not publicly available due to breaching individual privacy but deidentifiacted datasets are available from the corresponding author on reasonable request. A summary of data analysed during this study are included in this published article and its supplementary information files.

\section{Competing interests}

The authors declare that they have no competing interests.

\section{Funding}

This work was supported by the Swedish Research Council (K2007-70X-20514-01-3, K2010-70X-20514-04-3, 2017-01327) and Asia Link (348-2006-6633). ES is a recipient of a "Minor Field Study"-grant (2016-04-01) from the Swedish International Development Cooperation Agency and Stockholm University, Stockholm. The funding agencies did not interfere the study at any stage.

\section{Authors' contributions}

Designed the experiments: MS, CSL; Performed the experiments: MS, CSL; Conducted and responsible for the repeated training sessions for recording the data, for the coordination with the nurses, the monitoring and supervision of the data quality, data entry and cleaning of the data: MS; Analysed the data: ES, MS; Interpretation of the results: ES, CSL, CS, SV, MS; Wrote the paper: ES, CSL, CS, SV, MS. All authors read and approved the final manuscript.

\section{Acknowledgements}

The study would not be possible without the enormous contribution of the nurses at both hospitals for collecting the data. Thanks are also due to the management of both hospitals. The authors extend their thanks to Dr V. K. Mahadik (Medical Director) for the encouragement and providing support to conduct the study.

\section{Additional Files}

\section{Additional Files}

- File name: 190607_TableS1_BMC

- File format:.doc

- Title of the table S1: Classification of the ENT-inpatients in Surgical diagnoses sub-groups and Non-surgical diagnoses sub-groups 


\section{References}

1. World Health Organization. The evolving threat of antimicrobial resistance: Options for action [Internet]. Geneva: World Health Organization; 2012. [cited 2018 May 13]. Available from: http://apps.who.int/iris/bitstream/10665/44812/1/9789241503181_eng.pdf.

2. World Health Organization. Global Action Plan on Antimicrobial Resistance [Internet]. Geneva: World Health Organization; 2015. [cited 2018 April 25]. Available from: http://apps.who.int/iris/handle/10665/193736.

3. Chandy SJ, Thomas K, Mathai E, Antonisamy B, Holloway KA, Stalsby Lundborg C. Patterns of antibiotic use in the community and challenges of antibiotic surveillance in a lower-middle-income country setting: A repeated cross-sectional study in Vellore, South India. J Antimicrob Chemother. 2013;68(1):229-36.

4. Laxminarayan R, Chaudhury R. Antibiotic resistance in India: Drivers and opportunities for action. PLoS Med. 2016;13(3):e1001974.

5. Sharma M, Eriksson B, Marrone G, Dhaneria S, Lundborg CS. Antibiotic prescribing in two private sector hospitals; one teaching and one non-teaching: A cross-sectional study in Ujjain, India. BMC Infectious Diseases. 2012;12:155.

6. Leekha S, Terrell CL, Edson RS. General Principles of Antimicrobial Therapy. Mayo Clin Proc. 2011 Feb; 86(2):156-67.

7. Rehan HS, Kakkar AK, Goel S. Pattern of surgical antibiotic prophylaxis in a tertiary care teaching hospital in India. Int J Infect Control. 2009;6(2):ei2.014.10.

8. Sharma M, Damlin A, Pathak A, Stålsby Lundborg C. Antibiotic prescribing among pediatric inpatients with potential infections in two private sector hospitals in Central India. PLoS One. 2015 Nov;10(11):e0142317.

9. Kotwani A, Kumar S, Swain PK, Suri JC, Gaur SN. Antimicrobial drug prescribing patterns for communityacquired pneumonia in hospitalized patients: A retrospective pilot study from New Delhi, India. Indian J Pharmacol. 2015;47(4):375-82.

10. Pramil T, Sireesha Gudapati BN, Gombar S and D'Cruz S. Study of Parenteral Antimicrobial Therapy in ICUs of an Indian Public Teaching Hospital Using Glasgow Antimicrobial Audit Tool (GAAT). JPRCP. 2016;6(1):56-9.

11. World Health Organization. Regional Office for the Western Pacific. Public Hospital Governance in Asia and the Pacific - Comparative Country Studies, Vol. 1 No. 1 [Internet]. Manila: World Health Organization; 2015. [cited 2018 April 24]. Available from:

https://iris.wpro.who.int/bitstream/handle/10665.1/11361/9789290617112_eng.pdf.

12. Jesani A. Laws and Health Care Providers [Internet]. Maharashtra: Centre for Enquiry into Health and Allied Themes. 1996. [cited 2018 April 25]. Available from:

file:///C:/Users/Elisabeth/Downloads/A201547141930_1.pdf\%20(2).pdf.

13. Testa M, Stillo M, Giacomelli S, Scoffone S, Argentero PA, Farina CA et al. Appropriate use of antimicrobial prophylaxis: an observational study in 21 surgical wards. BMC Surg. 2015;15:63.

14. Carlin K, Löfmark S, Blad L. Swedish Work on Containment of Antibiotic Resistance [Internet]. Stockholm: Public Health Agency of Sweden. 2014. [cited 2018 April 15]. Available from:

https://www.folkhalsomyndigheten.se/contentassets/dae82c7afd424a57b57ec81818793346/swedish-workon-containment-of-antibiotic-resistance.pdf.

15. Raghavan U, Jones NS. Combating bacterial resistance in otorhinolaryngology. Clin Otolaryng Allied Sci. 2002;27(6):446-52. 
16. Anandhasayanam A, Kannan S, Sajir M, Zachariah N. Drug Prescription Pattern Observation at a ENT OPD Department in a Tertiary Care Hospital at Malappuram District of Kerala. Int J Pharm Sci Res. 2016;7(30):415763.

17. Nitasha Bhat GM, Holla R, Shrinath D and Kamath P. A study of prescription pattern in the drug therapy of ear, nose, and throat infections at a tertiary care hospital in Mangalore. Int J Basic Clin Pharmacol. 2015;4(4):68690.

18. WHO International Working Group for Drug Statistics Methodology, WHO Collaborating Centre for Drug Statistics Methodology, WHO Collaborating Centre for Drug Utilization Research and Clinical Pharmacological Services. Introduction to Drug Utilization Research [Internet]. Geneva: World Health Organization. 2003. [cited 2018 March 24]. Available from: http://apps.who.int/medicinedocs/pdf/s4876e/s4876e.pdf.

19. World Health Organization. Classifications of diseases, version 10 (ICD-10). Accessed 2008-2013. http://www.who.int/classifications/icd/en/.

20. World Health Organization. WHO Model List of Essential Medicines [Internet]. Geneva: World Health Organization. 2017. [cited 2018 February 15]. Available from:

http://www.who.int/medicines/publications/essentialmedicines/20th_EML2017_FINAL_amendedAug2017.pdf? $\mathrm{ua}=1$.

21. Ministry of Health \& Family Welfare. NLEM INDIA 2015 [Internet]. New Delhi: Government of India. 2015. [cited 2018 February 20]. Available from:]http://cdsco.nic.in/WriteReadData/NLEM-2015/NLEM,\%202015.pdf.

22. Scottish Intercollegiate Guidelines Network. Antibiotic Prophylaxis in Surgery 2014 [Internet]. Edinburgh: Healthcare Improvement Scotland. 2014. [cited 2017 November 15] Available from: http://www.sign.ac.uk/assets/sign104.pdf.

23. Bratzler D, Dellinger E, Olsen K, Perl TM, Auwaerter PG, Bolon MK et al. Clinical practice guidelines for antimicrobial prophylaxis in surgery. Am J Health Syst Pharm. 2013;70(3):195-283.

24. World Health Organization. Chronic Suppurative Otitis Media Burden of Illness and Management Options [Internet]. Geneva: World Health Organization. 2004. [cited 2018 January 16]. Available from: http://www.who.int/pbd/publications/Chronicsuppurativeotitis_media.pdf.

25. Bergman U, Popa C, Tomson Y, Wettermark B, Einarson TR, Åberg H, Sjöqvist F. Drug utilization $90 \%$ - a simple method for assessing the quality of drug prescribing. Eur J Clin Pharmacol. 1998;54(2):113-8.

26. Nagdeo N, Sonarkar R, Thombare VR, Akhtar M and Dasgupta S. Effects of an educational module in rationalizing surgical prophylaxis. Indian J Surg. 2015;77(4):290-6.

27. Khan S, Rao PGM, Rao A, Rodrigues G. Survey and evaluation of antibiotic prophylaxis usage in surgery wards of tertiary level institution before and after the implementation of clinical guidelines. Indian J Surg. 2006;68(3):150-6.

28. Diwan V, Gustafsson C, Rosales Klintz S, Joshi SC, Joshi R, Sharma M et al. Understanding Healthcare Workers Self-Reported Practices, Knowledge and Attitude about Hand Hygiene in a Medical Setting in Rural India. PLoS ONE. 11(10):e0163347.

29. Dhingra PL. Diseases of Ear, Nose, and Throat. Edition 7th, New Delhi: Elsevier India, 2017.

30. Johnson PE, Rickert SM, Jones J. Duration-Related Efficacy of Postoperative Antibiotics Following Pediatric Tonsillectomy: A Prospective, Randomized, Placebo-Controlled Trial. Arch Otolaryngol Head Neck Surg. 2009;135(10):984-7.

31. Fairbanks D. Pocket Guide to Antimicrobial Therapy in Otolaryngology - Head and Neck Surgery. Alexandira: The American Academy of Otolaryngology - Head and Neck Surgery Foundation, 2007. 
32. Saviteer SM, Samsa G, Rutala W. Nosocomial infections in the elderly. Increased risk per hospital day. Am J Med. 1988; 84(4):661-6.

33. Xavier Ottoline A, Tomita S, Marques MCP, Felix F, Ferraiolo PN, Santos Laurindo RS. Antibiotic prophylaxis in otolaryngologic surgery. Int Arch Otorhinolaryngol. 2013;17(1):85-91.

34. Sharma M, Sanneving L, Mahadik K, Santacatterina M, Dhaneria S and Stålsby Lundborg C. Antibiotic prescribing in women during and after delivery in a non-teaching, tertiary care hospital in Ujjain, India: a prospective cross-sectional study. Journal of Pharmaceutical Policy and Practice. 2013;6:9.

35. Tripathi KD. Essentials of Medical Pharmacology Edition 6th. New Delhi: Jaypee Brotthers Medical Publishers, 2008.

\section{Tables}

Table 1. The categories of ENT surgical wounds and the risk of surgical site infections as per available recommendations.

\begin{tabular}{llll} 
Categories & Surgical field at the ENT department & $\begin{array}{c}\text { Risk of } \\
\text { infection }\end{array}$ & $\begin{array}{l}\text { Recommendation } \\
\text { to prescribe } \\
\text { antibiotics }\end{array}$ \\
\hline Contaminated/dirty & $\begin{array}{l}\text { Areas of manifest infections, open wound } \\
>4 \text { hours }\end{array}$ & $>20 \%$ & Yes \\
\hline $\begin{array}{l}\text { Clean- } \\
\text { contaminated }\end{array}$ & $\begin{array}{l}\text { Penetration of mucosa in the oral cavity, } \\
\text { pharynx, larynx, oesophagus or nasal } \\
\text { cavity. Radical cancer surgery }\end{array}$ & $<10 \%$ & $\begin{array}{l}\text { Yes, as } \\
\text { prophylaxis }\end{array}$ \\
\hline Clean & $\begin{array}{l}\text { Sterile tissue or tissue that can be made } \\
\text { sterile, i.e., ear, sinus or skin, and } \\
\text { tonsillectomy, adenoidectomy. }\end{array}$ & $<2 \%$ & No \\
\hline
\end{tabular}

Abbreviations: ENT = Ear, nose and throat. The recommendations refer to the Scottish Intercollegiate Guidelines Network (2014) and Bratzler D, Dellinger E, Olsen K et al. Clinical practice guidelines for antimicrobial prophylaxis in surgery. Am J Health Syst Pharm 2013; 70: 195283

Table 2. The antibiotic prescription pattern at diagnosis group level at the ENT departments at the two study hospitals. 
$\begin{array}{ll}\text { Surgical diagnoses (Group A) } & \begin{array}{l}\text { Non-surgical diagnoses } \\ \text { (Group B) }\end{array}\end{array}$

CSOM

(Group

C)

\begin{tabular}{|c|c|c|c|c|c|c|c|c|}
\hline & & A1 & A2 & A3 & B1 & B2 & B3 & \\
\hline \multirow{2}{*}{$\begin{array}{l}\text { Total inpatients, } \\
\mathrm{n}(\%)\end{array}$} & $\mathrm{NTH}$ & $\begin{array}{l}101 \\
(15)\end{array}$ & $\begin{array}{l}45 \\
(7)\end{array}$ & $\begin{array}{l}198 \\
(29)\end{array}$ & $\begin{array}{l}65 \\
(10)\end{array}$ & $\begin{array}{l}37 \\
(5)\end{array}$ & $\begin{array}{l}89 \\
(13)\end{array}$ & $\begin{array}{l}140 \\
(20)\end{array}$ \\
\hline & $\mathrm{TH}$ & $\begin{array}{l}182 \\
(8)\end{array}$ & $\begin{array}{l}270 \\
(12)\end{array}$ & $\begin{array}{l}679 \\
(31)\end{array}$ & $\begin{array}{l}96 \\
(4)\end{array}$ & $\begin{array}{l}42 \\
(2)\end{array}$ & $\begin{array}{l}208 \\
(9)\end{array}$ & $\begin{array}{l}743 \\
(33)\end{array}$ \\
\hline \multirow{2}{*}{$\begin{array}{l}\text { Prescribed AB, } \\
\text { n (\%) }\end{array}$} & $\mathrm{NTH}$ & $\begin{array}{l}97 \\
(96)\end{array}$ & $\begin{array}{l}43 \\
(96)\end{array}$ & $\begin{array}{l}162 \\
(81)\end{array}$ & $\begin{array}{l}60 \\
(92)\end{array}$ & $\begin{array}{l}29 \\
(78)\end{array}$ & $\begin{array}{l}67 \\
(75)\end{array}$ & $\begin{array}{l}125 \\
(89)\end{array}$ \\
\hline & $\mathrm{TH}$ & $\begin{array}{l}171 \\
(94)\end{array}$ & $\begin{array}{l}250 \\
(93)\end{array}$ & $\begin{array}{l}584 \\
(86)\end{array}$ & $\begin{array}{l}90 \\
(94)\end{array}$ & $\begin{array}{l}37 \\
(88)\end{array}$ & $\begin{array}{l}173 \\
(83)\end{array}$ & $\begin{array}{l}706 \\
(95)\end{array}$ \\
\hline \multirow{2}{*}{$\begin{array}{l}\text { Duration of hospital } \\
\text { stay in days, } \\
\text { median (range) }\end{array}$} & $\mathrm{NTH}$ & $\begin{array}{l}3(1- \\
16)\end{array}$ & $\begin{array}{l}4(2- \\
17)\end{array}$ & $\begin{array}{l}3(1- \\
25)\end{array}$ & $\begin{array}{l}3(1- \\
11)\end{array}$ & $\begin{array}{l}2(1- \\
6)\end{array}$ & $\begin{array}{l}3(1- \\
10)\end{array}$ & $\begin{array}{l}4(1- \\
32)\end{array}$ \\
\hline & $\mathrm{TH}$ & $\begin{array}{l}7(1- \\
40)\end{array}$ & $\begin{array}{l}7(1- \\
48)\end{array}$ & $\begin{array}{l}8(1- \\
77)\end{array}$ & $\begin{array}{l}8(1- \\
22)\end{array}$ & $\begin{array}{l}5(1- \\
36)\end{array}$ & $\begin{array}{l}7(1- \\
58)\end{array}$ & $\begin{array}{l}11 \\
38)\end{array}$ \\
\hline \multirow{2}{*}{$\begin{array}{l}\text { Duration of AB } \\
\text { treatment in days, } \\
\text { median (range) }\end{array}$} & $\mathrm{NTH}$ & $\begin{array}{l}3(1- \\
12)\end{array}$ & $\begin{array}{l}4(2- \\
9)\end{array}$ & $\begin{array}{l}3(1- \\
25)\end{array}$ & $\begin{array}{l}4(1- \\
11)\end{array}$ & $\begin{array}{l}3(1- \\
6)\end{array}$ & $\begin{array}{l}3(1- \\
9)\end{array}$ & $\begin{array}{l}4(1- \\
14)\end{array}$ \\
\hline & $\mathrm{TH}$ & $\begin{array}{l}8(1- \\
23)\end{array}$ & $\begin{array}{l}7(1- \\
47)\end{array}$ & $\begin{array}{l}8(1- \\
64)\end{array}$ & $\begin{array}{l}8(1- \\
23)\end{array}$ & $\begin{array}{l}5(1- \\
11)\end{array}$ & $\begin{array}{l}7(1- \\
57)\end{array}$ & $\begin{array}{l}11 \\
36)\end{array}$ \\
\hline \multirow{2}{*}{$\begin{array}{l}\text { Total prescriptions, } \\
\text { n (\%) }\end{array}$} & $\mathrm{NTH}$ & $\begin{array}{l}509 \\
(20)\end{array}$ & $\begin{array}{l}190 \\
(8)\end{array}$ & $\begin{array}{l}657 \\
(26)\end{array}$ & $\begin{array}{l}248 \\
(10)\end{array}$ & $\begin{array}{l}98 \\
(4)\end{array}$ & $\begin{array}{l}251 \\
(10)\end{array}$ & $\begin{array}{l}569 \\
(23)\end{array}$ \\
\hline & $\mathrm{TH}$ & $\begin{array}{l}2261 \\
(11)\end{array}$ & $\begin{array}{l}2224 \\
(11)\end{array}$ & $\begin{array}{l}5302 \\
(26)\end{array}$ & $\begin{array}{l}889 \\
(4)\end{array}$ & $\begin{array}{l}251 \\
(1)\end{array}$ & $\begin{array}{l}1727 \\
(9)\end{array}$ & $\begin{array}{l}7648 \\
(38)\end{array}$ \\
\hline \multirow[t]{2}{*}{ DDD/100 prescriptions } & $\mathrm{NTH}$ & 172.2 & 164.7 & 156.7 & 129.4 & 147.5 & 145.2 & 126.9 \\
\hline & $\mathrm{TH}$ & 75.8 & 89.8 & 85.4 & 82.6 & 80.3 & 87.9 & 90.9 \\
\hline \multirow{2}{*}{$\begin{array}{l}\text { Prescriptions adherent } \\
\text { to WHOLEM and } \\
\text { NLEM, }\end{array}$} & $\mathrm{NTH}$ & $86 / 85$ & $75 / 75$ & $74 / 75$ & $76 / 78$ & $92 / 85$ & $66 / 68$ & $76 / 75$ \\
\hline & $\mathrm{TH}$ & $82 / 80$ & $83 / 81$ & $80 / 80$ & $80 / 80$ & $84 / 84$ & $85 / 85$ & $90 / 90$ \\
\hline \multirow{2}{*}{$\begin{array}{l}\text { *Adherence to } \\
\text { international } \\
\text { prescribing } \\
\text { guidelines, \% }\end{array}$} & NTH & 60 & 22 & 25 & - & - & - & 18 \\
\hline & $\mathrm{TH}$ & 40 & 10 & 11 & - & - & - & 10 \\
\hline \multirow{2}{*}{$\begin{array}{l}\text { AB prescribed by } \\
\text { parenteral route of } \\
\text { administration, } \%\end{array}$} & $\mathrm{NTH}$ & 99 & 94 & 85 & 96 & 85 & 94 & 96 \\
\hline & $\mathrm{TH}$ & 85 & 59 & 64 & 72 & 68 & 68 & 68 \\
\hline \multirow{2}{*}{$\begin{array}{l}\text { AB prescribed using } \\
\text { generic name, } \%\end{array}$} & NTH & 14 & 4 & 5 & 4 & 2 & 2 & 5 \\
\hline & $\mathrm{TH}$ & 46 & 37 & 39 & 39 & 37 & 42 & 54 \\
\hline
\end{tabular}

*The international prescribing guidelines refer to the Scottish Intercollegiate Guidelines Network (2014) and Bratzler D, Dellinger E, Olsen K et al. Clinical practice guidelines for antimicrobial prophylaxis in surgery. Am J Health Syst Pharm 2013; 70: 195-283. 
Abbreviations: A1 = Contaminated/dirty surgery; A2 = Clean-contaminated surgery; A3 = Clean surgery; B1 = Clinical infection of bacterial, fungal or parasitic origin; B2 = Clinical infection of viral origin; $\mathrm{B} 3$ = Non-infectious diseases; $\mathrm{CSOM}=$ Chronic suppurative otitis media; $\mathrm{TH}=$ Teaching hospital; NTH = Non-teaching hospital; ENT = Ear, nose and throat; $\mathrm{AB}=$ Antibiotics; $\mathrm{n}=\mathrm{Number}$; WHOLEM = WHO list of essential medicines; NLEM = National list of essential medicines in India;

\section{Figures}

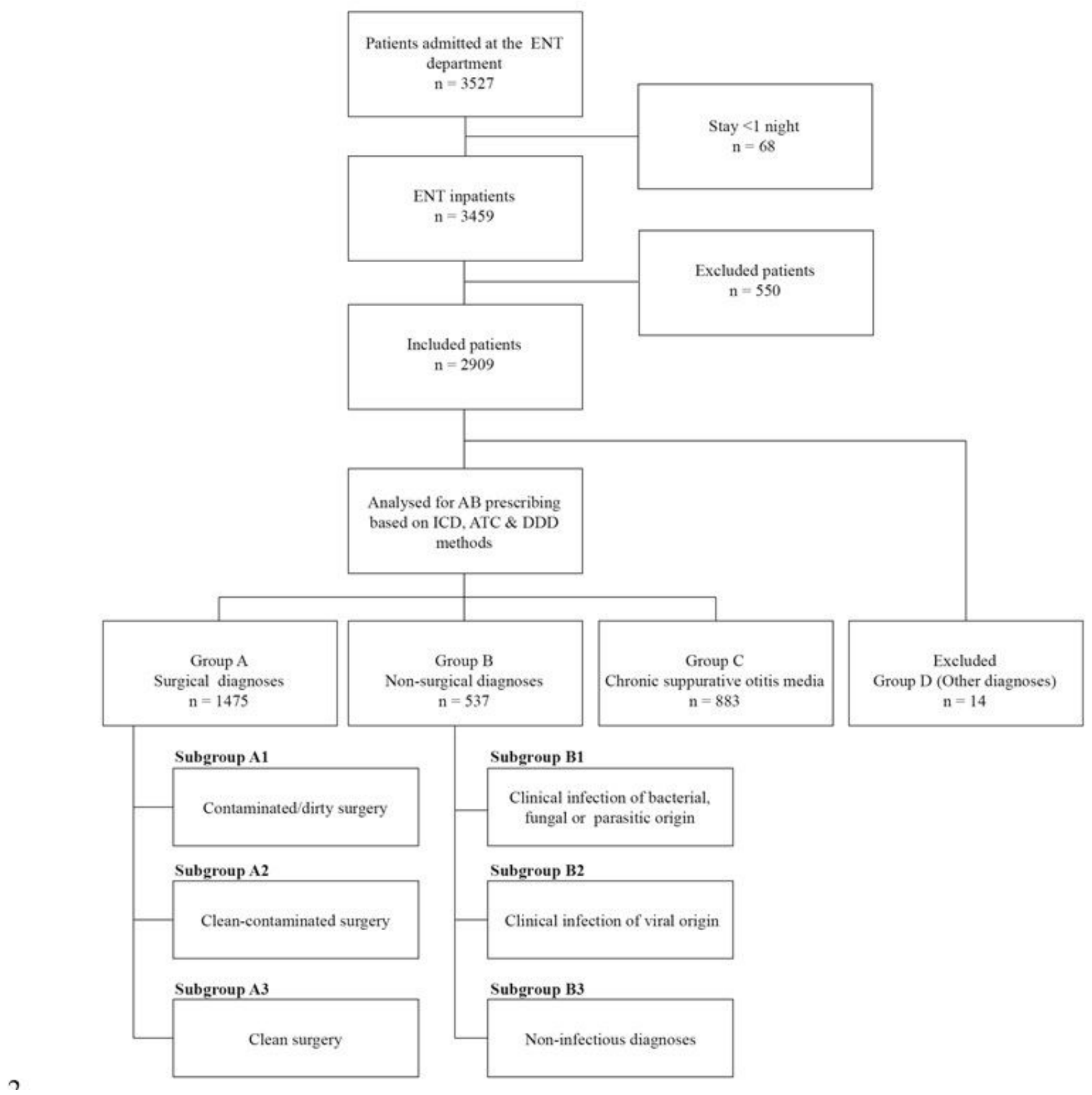

Figure 1 
The division of diagnoses in groups (A-D) and subgroups (1-3). Abbreviations: ENT = otorhinolaryngology; $n=$ numbers; ICD-10 = International Classification of Diseases, version 10 by the World Health Organization

(\% of prescriptions)
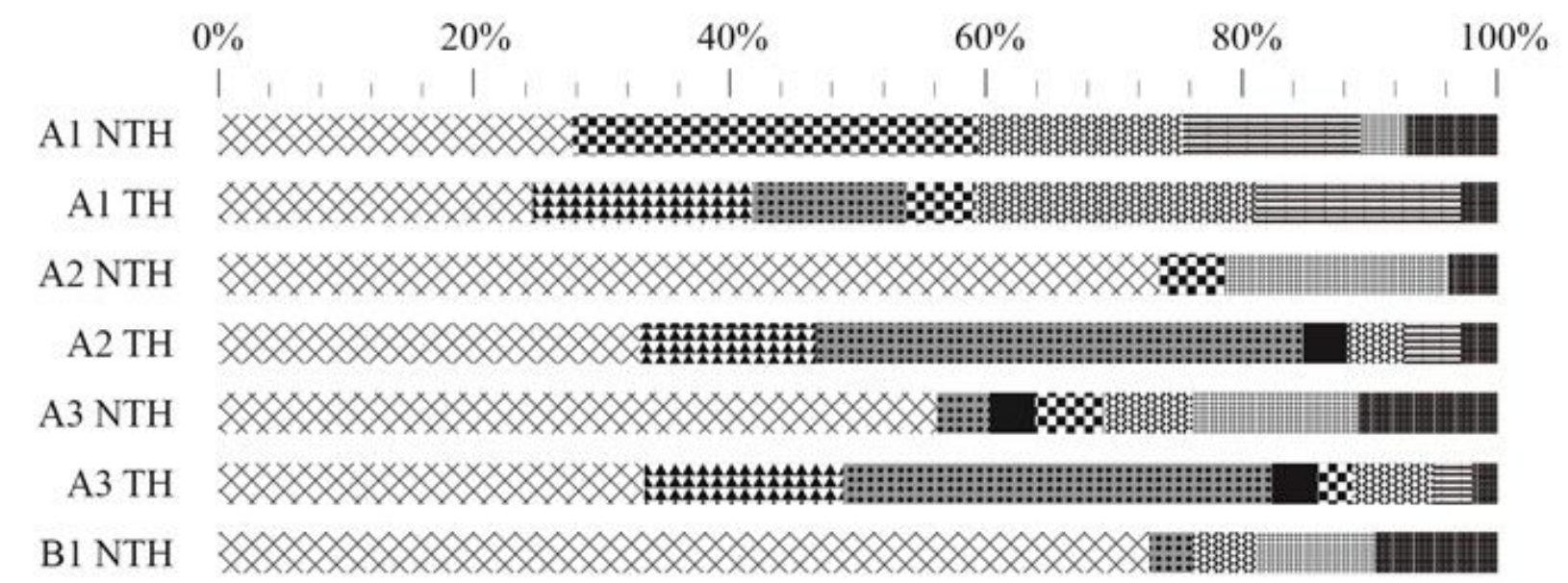

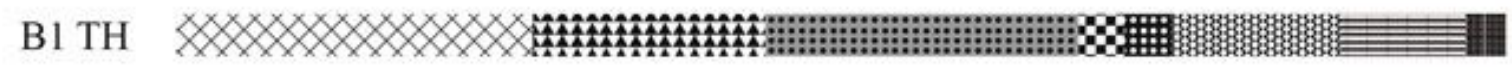

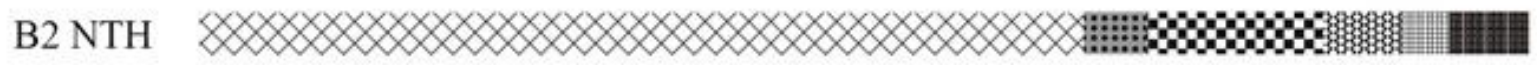

B2 TH

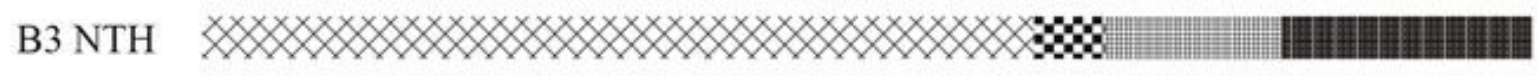

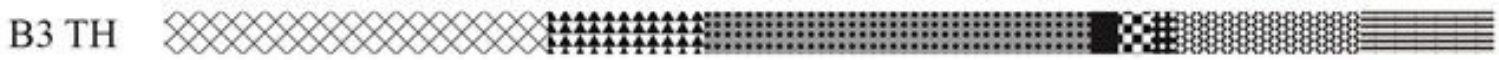

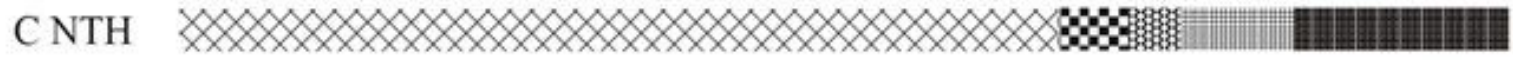

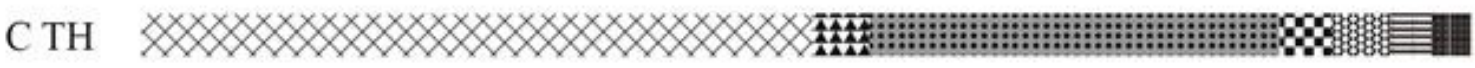

\begin{tabular}{|c|c|}
\hline J01DD04: Ceftriaxone & 坢 J01DD01: Cefotaxime \\
\hline J01CR50: Ampicillin with cloxacillin & J01GB03: Gentamycin \\
\hline J01MA02: Ciprofloxacin & J01XD01: Metronidazole \\
\hline J01AA02: Doxycycline & J01DC02: Cefuroxime \\
\hline J01CR02: Amoxicillin with clavulanic acid & $\begin{array}{l}\text { J01RA } 84 \text { and } 85 \text { : Ceftriaxone } \\
\text { with sulbactam and tazabactam } \\
\text { respectively }\end{array}$ \\
\hline
\end{tabular}

Figure 2

Selection of prescribed antibiotics at diagnosis subgroup level using the DU90 approach. $100 \%$ in the graphs represents $100 \%$ of the DU90 method by U. Bergman et. al. Drug utilization $90 \%$, a simple method for assessing the quality of drug prescribing. Eur J Clin Pharmacol (1998) 54: 113-11. Abbreviations: A1 = Contaminated/dirty surgery; $\mathrm{A} 2$ = Clean-contaminated surgery; $\mathrm{A} 3$ = Clean surgery; $\mathrm{B} 1$ = Clinical infection of bacterial, fungal or parasitic origin; B2 = Clinical infection of viral origin; B3 = Non-infectious diseases; C = Group C, i.e. chronic suppurative otitis media; TH = Teaching hospital; NTH = Non-teaching hospital. 


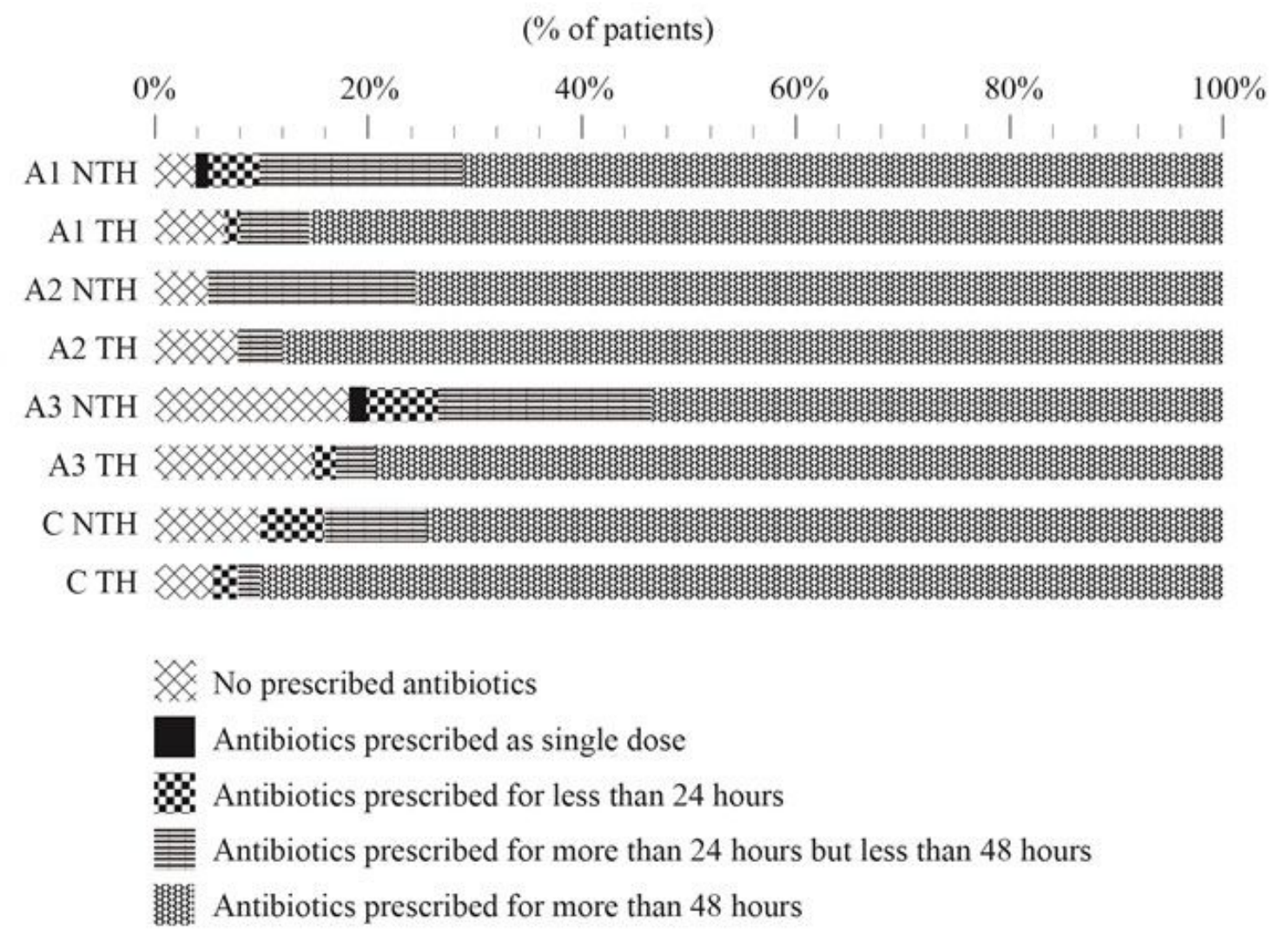

\section{Figure 3}

Duration of antibiotic treatment to the patients of Group $A$ and $C$ in the study hospitals. Abbreviations: $A 1=$ Contaminated/dirty surgery; $\mathrm{A} 2$ = Clean-contaminated surgery; $\mathrm{A} 3$ = Clean surgery; C = Group C, i.e. chronic suppurative otitis media; $\mathrm{TH}=$ Teaching hospital; $\mathrm{NTH}=$ Non-teaching hospital

\section{Supplementary Files}

This is a list of supplementary files associated with this preprint. Click to download.

- 190607TableS1BMC.docx 